\title{
Seramik Karoların Altın Dekorasyonunda Katodik Ark- FBB TiN Kaplama Proses Parametrelerinin Optimizasyonu
}

\author{
Belgin Tanışan ${ }^{1}$, Tugay Tosun ${ }^{1}$ \\ ${ }^{1}$ Eskişehir Osmangazi Üniversitesi, Mühendislik Mimarlık Fakültesi, Metalurji ve Malzeme Mühendisliği Bölümü, \\ Eskişehir. \\ e-posta: btanisan@ogu.edu.tr \\ ORCID ID: http://orcid.org/0000-0002-5922-6632
}

Geliş Tarihi: 19.04.2018 ; Kabul Tarihi: 29.03.2019

Öz

$\begin{array}{cl}\text { Anahtar kelimeler } & \text { FBB proses parametrelerinin optimizasyonu amaçlanmıştır. Kaplama ünitesinde; altılı malzemesi olarak } \\ \text { TiN kaplama; } & \text { sırlı seramik karolar, katot olarak saf Ti diskler ve reaktif gaz olarak da nitrojen }\left(\mathrm{N}_{2}\right) \text { kullanılmıştır. } \\ \text { Katodik Ark FBB; } & \text { Kaplama işlemi; sabit biriktirme süresinde }(90 \mathrm{sn}) \text {, katod akımı }(100-150-200 \mathrm{~A}) \text { ve } \mathrm{N}_{2} \text { akış oranı }(550- \\ \text { Seramik karo; } & 650-750 \mathrm{sccm}) \text { değiştirilerek gerçekleştirilmiştir. Üretilen kaplamaların } L^{*} a^{*} b^{*} \text { renk parametreleri } \\ \text { Dekorasyon } & \text { spektrafotometre ile ölçülmüş ve ticari TiN kaplamaların } L^{*} a^{*} b^{*} \text { değerleri ile karşıllaştırılmıştır. Sonuç } \\ & \text { olarak, TiN stokiyometrisine yakın olduğu düşünülen proses parametreleri ile }(550 \mathrm{sccm}-150 \mathrm{~A} \text { ve } 650 \\ & \mathrm{sccm}-200 \mathrm{~A}) \text { ticari TiN kaplamalara benzer altın renginde kaplamalar üretilmiştir. }\end{array}$

\section{Optimization of Cathodic Arc-PVD TiN Coating Process Parameters on the Gold-like Decoration of Ceramic Tiles}

\begin{abstract}
In this study, the optimization of Cathodic Arc PVD process parameters to obtain gold-like colour TiN coating Keywords TiN coating; Cathodic Arc PVD; Ceramic tile; Decoration
\end{abstract}

\section{Giriş}

Bir malzeme yüzeyinin farklı yöntemlerle başka bir malzeme ile kaplanması; malzeme yüzeyinin fonksiyonel ve dekoratif özelliklerini ya da bu özelliklerin her ikisini de değiştirmek amacıyla yapılmaktadır. Kaplama işlemi kaplanan malzemenin kullanılacağı ortama göre malzemenin tüm yüzeyine ya da belirli bir kısmına uygulanabilir. Kaplama yöntemleri arasında Fiziksel Buhar Biriktirme (FBB) yöntemleri; çevre dostu olması, ekonomik olarak seri üretime olanak sağlaması, üretilen kaplamaların yüksek aşınma dayanımları ve estetik görünümleri nedeniyle endüstrinin farklı dallarında geniş kullanım alanı bulmuştur (Öncel 2002).

FBB tekniği, vakum altında katı bir malzemenin buharlaştırılarak ya da sıçratılarak atomlarının yüzeyinden koparılması ve kaplanacak olan malzeme yüzeyine biriktirilmesi esasına dayanır. Buharlaştırma yöntemi ile üretilen kaplamalar için gerekli olan buhar fazı, rezistanlı, elektron bombardımanlı ya da katodik arklı buharlaştırma 
yöntemleri yardımıyla sağlanmaktadır (Richert et al. 2010, Kim et al. 2007, Manova et al. 2010). Katodik Ark FBB yöntemiyle üretilen kaplamalar; yüksek iyonizasyon ve biriktirme oranı ile diğer kaplamalara göre; çok daha iyi yüzey kalitesi, yüksek yapışma mukavemeti, üniform kaplama kalınlığı ve daha iyi mekanik özellikler sergilerler. Sağladığı bu avantajlar endüstriyel uygulamalarda ve bilimsel araştırmalarda bu tekniğe olan ilgiyi arttırmıştır (Larpkiattaworn et al. 2013).

Katodik Ark FBB sisteminin şematik görünümü Şekil 1 'de verilmiştir. Burada, vakum ortamında buharlaştırılacak olan malzeme katot (hedef metal), kaplanacak olan altlık malzemesi ise anot olarak yerleştirilir. Bu yöntemde hedef metalinin buharlaştırılması ve iyonize olması amacıyla, düşük voltaj (10-40 V) ve yüksek akım (30-300 A) ile katot yüzeyinde "ark" meydana getirilir. Arkın oluştuğu noktalarda, sıcaklığın çok yüksek değerlere $\left(\sim 2500^{\circ} \mathrm{C}\right)$ ulaşması sonucunda, bu noktalarda sırasıyla önce ergime ve sonrasında da buharlaşma gerçekleşir. Buharlaştırılarak katot yüzeyinden koparılan iyonlar reaktif gazlarla plazma haline getirilerek kaplanacak olan altlık malzeme yüzeyine biriktirilir (Sönmezoğlu vd. 2012, Mubarak et al. 2005).

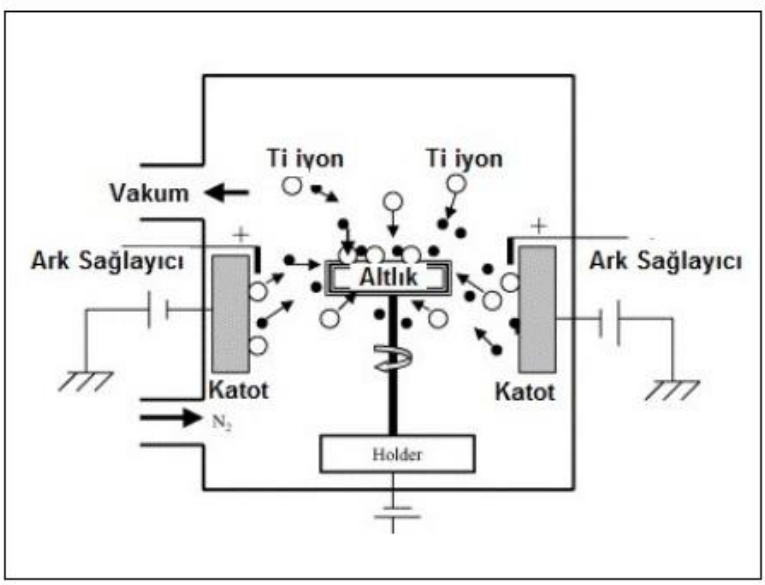

Şekil 1. Katodik Ark FBB sisteminin şematik görünümü

Katodik Ark FBB yöntemi ile aşınmaya dayanıklı dekoratif kaplamaların ilk uygulamaları 1970'li yılların ikinci yarısında başlamıştır. Bu yıllarda altın fiyatlarındaki artış; değerli kol saati ve imitasyon takı üreticileri ile FBB teknolojisinde uzmanlaşmış firmaları altın kaplamanın yerini alabilecek aşınmaya dayanıklı seramik kaplamaların geliştirilmesi konusuna yöneltmiştir (Öncel 2002). Bu yöntem ile metalik renklerde kaplamalar iki şekilde oluşturulmaktadır: Birincisi, katot olarak kullanılan hedef metalinin kendi rengidir. Burada vakum odasında inert gaz atmosferinde titanyum, zirkonyum, tantalyum ve krom gibi hedef metallerin kendi renkleri renklendirmeyi sağlar. İkincisinde ise renklendirme vakum odasına bir ya da birden fazla reaktif gazın beslenmesiyle gerçekleştirilir. Burada, argon ve azot gazlarının birlikte beslenmesiyle bu metallerin nitrürlü bileşikleri ( $\mathrm{TiN}, \mathrm{ZrN}, \mathrm{CrN}$ ) ya da argon, azot ve hidrokarbon gaz karışımının birlikte beslenmesiyle karbonitrürlü bileşikleri (TiCN) elde edilir. Renklenme temel olarak seçilen hedef metalinin bileşimine ve biriktirme sırasında vakum odasına beslenen reaktif gazların oranına bağlıdır (Alberdi et al. 2005).

Titanyum nitrür (TiN) kaplamalar; yüksek sertlikleri, düşük aşınma oranları ve estetik görünümleri nedeniyle aşınmayı önleme ve dekoratif amaçlı olarak yaygın kullanım alanı bulmuşlardır. Günümüzde dekoratif TiN kaplamalar sahip oldukları altın sarısı renkleri ve yüksek aşınma dayanımı ile geleneksel altın kaplamaların yerini almıştır. TiN sert kaplamalar yüzey renklendirmesi sağlamasının yanı sıra kaplandığı altlık malzemesini korozyon ve aşınmaya karşı da korurlar (Vaz et al. 2002, Lousa et al. 2007, Niyomsoan et al. 2002). Literatürde TiNx ince film kompozisyonunun stokiyometrik değişiminin, bu kaplamaların yansıtma (parlaklık) ve renk özelliklerini önemli ölçüde etkilediği belirtilmektedir. Özellikle katot akımı, reaktif gaz akış oranı ve kaplama süresi ile farklı kompozisyonda ve renklerde TiNx kaplamalar elde edilebilmektedir. İdeal altın renklendirme stokiyometrik TiNx $(x=1)$ bileşimi ile ifade edilirken, kompozisyonda $\mathrm{N} / \mathrm{Ti}$ oranının artmasıyla $(x>1)$ bakır-kahve, $N / T i$ oranının azalmasıyla $(x<1)$ ise açık altın-gümüş renk oluşumu gerçekleşmektedir (Zeghni 2003, Lousa et al. 2007).

Günümüzde seramik karoların metalik renklendirilmesinde iki farklı yöntem uygulanmaktadır: Karo yüzeyinin tamamının metalik 
renklendirilmesi istenildiğinde belirli oranda kıymetli metal tozu (altın, platin) pişmiş karo yüzeyine dağıtılır sonrasında sırlama ve pişirme işlemleri uygulanır. Ancak, sinterleme sonrasında bu ürünlerin hem çizilme mukavemetleri hem de kimyasallara karşı dayanımları çok düşüktür ve bu nedenle de zemin ve dış cephe uygulamalarında kullanıma uygun değildirler. Diğer bir uygulama şekli ise, sır pişirimi yapılmış karo yüzeyine kıymetli metal tozlarının ilavesiyle özel olarak hazırlanmış pastaların elek baskı tekniği ile karo yüzeyinde istenilen kısımlara uygulanması ve sonrasında dekor fırınında pişirilerek metalik renklendirilmesi şeklindedir. Bu uygulama ile görsel olarak etkili metalik renklendirme sağlanmasına karşın, diğer uygulamaya benzer şekilde çizilme mukavemeti ve kimyasallara karşı dayanımları düşüktür. Bunlara ilaveten kıymetli metal tozlarının yüksek fiyatları ve dekor pişirme prosesinin getirdiği ilave maliyet bu tekniğin seramik karo dekorasyonunda kullanımını kısıtlamaktadır (Alberdi et al. 2005).

Son yıllarda vakum teknolojisinin iyileştirilmesi, ucuzlaması ve kaplama parametreleri kontrol edilebilen büyük hacimli kaplama sistemlerinin geliştirilmesi ile düşük maliyette estetik görünümlü FBB sert seramik kaplamaların farklı endüstri kollarında kullanılmasına olanak sağlamıştır. Seramik ürünlerde FBB sert kaplamaların dekoratif amaçıı kullanımı çok yeni olup; hali hazırda Katodik Ark FBB tekniği ile lavabo, porselen mutfak eşyası ve seramik karolar farklı metalik renklerde kaplanmaktadır (Şekil 2). Bu çalışmada, Katodik Ark FBB yöntemi ile sırlı seramik karo yüzeyleri TiN bileşiminde altın benzeri renkte kaplanması amaçlanmıştır. Üretilen kaplamaların $L^{*} a * b *$ renk parametrelerine kaplama ünitesine beslenen reaktif nitrojen gaz akış oranının (debisinin) ve katot akımının etkisi araştırıımış ve ticari TiN kaplamalara benzer altın renklerde kaplamalar üretmek için proses parametrelerinin optimizasyonu yapılmıştır.

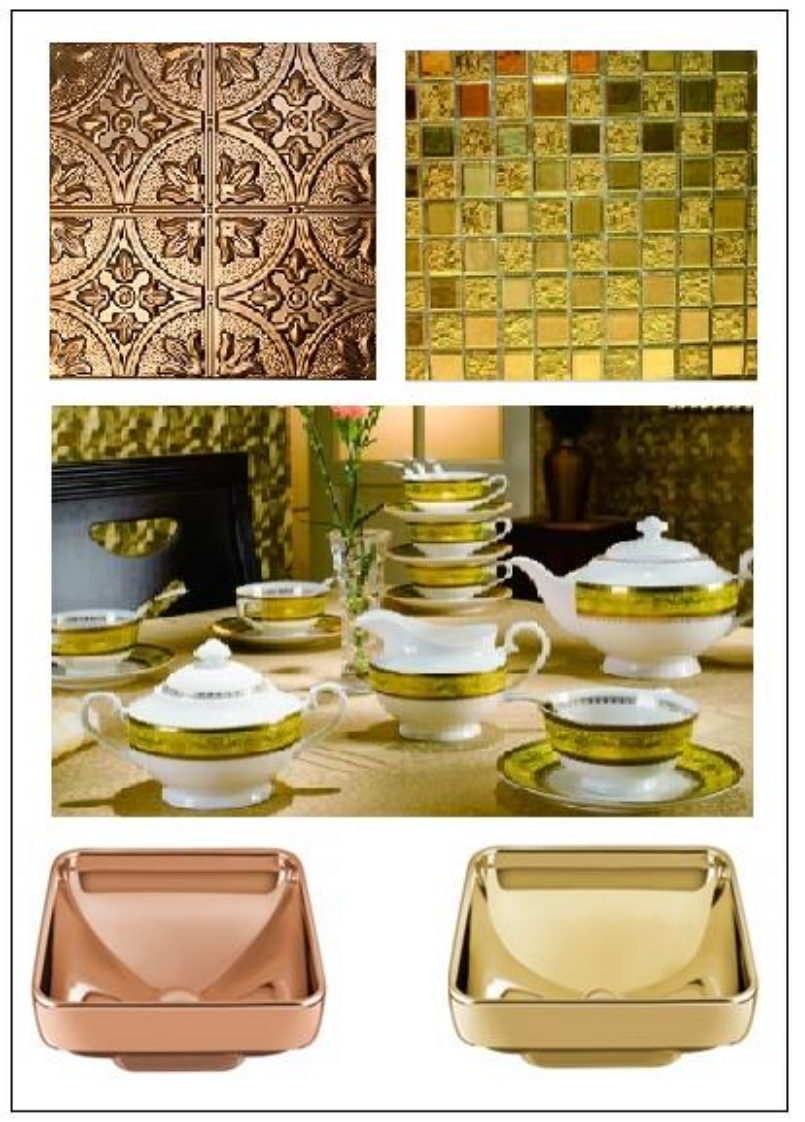

Şekil 2. Katodik Ark FBB tekniği ile dekoratif amaçlı kaplanmış seramik ürünler

\section{Deneysel Çalışmalar}

\subsection{Materyal ve Metot}

Deneysel çalışmalarda kaplama (alt/ık) malzemesi olarak $10 \times 20 \mathrm{~cm}$ ebatlarında beyaz renkte sırlı porselen karolar kullanılmış ve kaplama işlemleri endüstriyel Katodik Ark FBB kaplama ünitesinde gerçekleştirilmiştir. Porselen karolar kaplama işlemi öncesinde ön ısıtma kabininde $300{ }^{\circ} \mathrm{C}$ sıcaklıkta 30 dakika süreyle ısıtma işlemi sonrasında kaplama ünitesine yerleştirilmiştir (Şekil 3). Kaplama ünitesinde katot olarak 36 adet \%99,99 saflıkta $\mathrm{Ti}$ diskler kullanılmıştır. Kaplama işleminde inert ve reaktif gaz olarak sırasıyla ticari saflıkta Argon (Ar) ve Nitrojen $\left(\mathrm{N}_{2}\right)$ gazları kullanılmıştır. Kaplama işlemleri, $150{ }^{\circ} \mathrm{C}$ sıcaklıkta, 0,03 Pa vakum basıncı altında gerçekleştirilmiştir.

Deneysel çalışmalarda TiN stokiyometrisine dolayısıyla da ideal altın renklendirme için en yakın proses parametrelerini belirlemek amacıyla kaplama ünitesine beslenen $\mathrm{N}_{2}$ gaz debisi ve Ti 
disklere uygulanacak katot akımının farklı kombinasyonları ile kaplama işlemleri gerçekleştirilmiştir. Altlık yüzeyi ve TiN kaplama tabakası arasında adhezyonu sağlamak için tüm numuneler başlangıçta 90 sn süreyle $200 \mathrm{sccm}$ debiyle beslenen $\mathrm{Ar}$ gazı ortamında metalik $\mathrm{Ti}$ ile kaplandıktan sonra sisteme $\mathrm{N}_{2}$ gazı beslenerek $90 \mathrm{sn}$ süreyle TiN kaplama işlemi gerçekleştirilmiştir. Çizelge 1'de deneysel çalışmalarda kullanılan kaplama parametreleri verilmiştir.

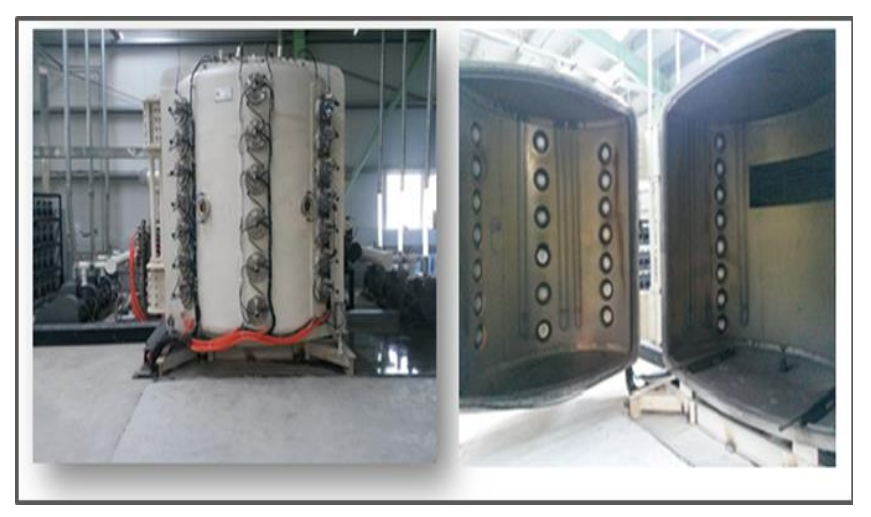

Şekil 3. Deneysel çalışmalarda kullanılan kaplama kabinin dış ve iç görünümü

Çizelge 1. Deney numunelerine ait kaplama parametreleri

\begin{tabular}{llll}
\hline Numune & $\begin{array}{l}\mathbf{N}_{2} \text { Debisi } \\
\text { (sccm- } \\
\left.\mathbf{c m}^{\mathbf{3}} \mathbf{d d k}\right)\end{array}$ & $\begin{array}{l}\text { Katod } \\
\text { Akımı } \\
\text { (A) }\end{array}$ & $\begin{array}{l}\text { Kaplama } \\
\text { Süresi (sn) }\end{array}$ \\
\hline K550-100 & 550 & 100 & 90 \\
\hline K650-100 & 650 & 100 & 90 \\
\hline K750-100 & 750 & 100 & 90 \\
\hline K550-150 & 550 & 150 & 90 \\
\hline K650-150 & 650 & 150 & 90 \\
\hline K750-150 & 750 & 150 & 90 \\
\hline K550-200 & 550 & 200 & 90 \\
\hline K650-200 & 650 & 150 & 90 \\
\hline K750-200 & 750 & 200 & 90 \\
\hline
\end{tabular}

\subsection{Kaplamaların Renk Ölçümleri}

Kaplamaların renkleri CIE L*a*b* renk modeline göre spektrafotometre cihazı (Minolta CM 3600d) kullanılarak ölçülmüş ve bu değerlerden görünür bölgeye ait (400-700 nm) spektral reflektans (yansıtma) eğrileri çizilmiştir. CIEL*a*b* renk modeline göre $L^{*}$ parametresi $0-100$ arasında değişen değerlerde olup renk açıklığını ifade etmektedir ( $L^{*}=0$ siyah $L^{*}=100$ beyaz). $a^{*}$ ve $b^{*}$ renk tonunu ifade eden parametreler olup; $a^{*}<0$ yeşil, $a^{*}>0$ kırmıı ve $b^{*}<0$ mavi, $b^{*}>0$ sarı rengi karakterize eder.

\section{Bulgular ve Tartışma}

Çizelge 2'de farklı proses parametreleriyle Katodik Ark FBB tekniği ile kaplanan seramik karo numunelerinin spektrafotometre cihazı ile ölçülen $L^{*} a * b *$ renk parametreleri verilmiştir. Çizelgede ayrıca, üretilen kaplamaların renk parametrelerini kıyaslamak amacıyla literatürde yer alan ticari TiN kaplamalara ait renk parametreleri de yer almaktadır. Şekil 4'de ise kaplanan numunelerin $L^{*} a * b *$ renk parametrelerine göre görünür bölgeye ait reflektans (yansıtma) grafikleri ve dijital fotoğraf görüntüleri verilmiştir.

Çizelge 2 ve Şekil 4 incelendiğinde $\mathrm{N}_{2}$ akış oranı ve katot akımının farklı kombinasyonları ile kaplanan numunelerde farklı altın tonlarının yanı sıra kahve, bakır, yeşil, mor gibi renklerin de oluştuğu görülmektedir. Bu sonuçlardan altın dışındaki renklerin TiN stokiyometrisini karşılamayan proses parametreleri neticesinde oluştuğu düşünülmüştür. Kaplama işlemi sırasında Ti katotlara uygulanan akım sayesinde Ti iyonları katot yüzeyinden koparak plazmaya gönderilmekte ve sisteme nitrojen gazı verilmesiyle plazmadaki $\mathrm{Ti}$ iyonları $\mathrm{N}_{2}$ gazı ile tepkimeye girerek altlık yüzeyinde TiN bileşiği olarak birikmektedir. Dekoratif amaçlı TiN kaplamalar için ideal altın renk kompozisyondaki nitrojen ve titanyum atomlarının stokiyometrik oranı $(\mathrm{N} / \mathrm{Ti}=1)$ ile ifade edilmektedir. Nitrojen miktarı altın renk oluşumunda önemli olup, N/Ti oranı arttırıldığında daha koyu altın tonlarında renk oluşmaktadır (Alves et al. 2015, Niyomsoan et al. 2002). Bu bağlamda 
üretilen kaplamaların rengi $\mathrm{N} / \mathrm{Ti}$ oranı ile ilişkilendirecek açıklanmıştır:

K550-100, K650-100, K750-100 serisi kaplamalarda artan nitrojen ile kaplamaların rengi bakır-yeşil-mor olarak değişmiştir. Bu renk değişimi stokiyometrik olmayan proses koşullarından kaynaklanmaktadır. $100 \mathrm{~A}$ akım için uygulanan en düşük nitrojen miktarı (550 sccm) fazla gelmiş ve bakır renk oluşmuştur. $\mathrm{N} / \mathrm{Ti}$ oranı düşürüldüğünde renk bakırdan altına değişeceği için bu serideki kaplamaların daha düşük nitrojen miktarına $\left(\mathrm{N}_{2}<550 \mathrm{sccm}\right)$ ihtiyacı olduğu söylenebilir.

K550-150, K650-150, K750-150 serisi kaplamalarda artan nitrojen miktarı ile kaplamaların rengi altınbakır-yeşil olarak değişmiştir. N/Ti=1 stokiyometrisine en yakın proses koşulları K550-150 numunesi ile elde edilmiş olup, buradan altın renginde kaplamalar üretmek için $150 \mathrm{~A}$ katot akımı ve $550 \mathrm{sccm} \mathrm{N} \mathrm{N}_{2}$ debisinin yeterli olacağı söylenebilir.

K550-200, K650-200, K750-200 serisi kaplamalarda artan nitrojen miktarı ile açıktan koyuya değişen altın tonlarında kaplamalar üretilmiştir. Bu serideki numunelerle $\mathrm{N} / \mathrm{Ti}=1$ stokiyometrisine en yakın proses koşulları K650-200 numunesi ile elde edilmiş olup, buradan 200 A katot akımı için $650 \mathrm{sccm} \mathrm{N}$ debisinin yeterli olacağı söylenebilir.

Çizelge 2. Kaplamaların spektrafotometre ile belirlenen $L^{*} a * b *$ renk parametreleri

\begin{tabular}{lccc}
\hline \multirow{2}{*}{ Numune } & \multicolumn{3}{c}{ CIE L*a*b* Renk Parametreleri } \\
\cline { 2 - 4 } & $\mathbf{L}^{*}$ & $\mathbf{a}^{*}$ & $\mathbf{b}^{*}$ \\
\hline K550-100 & 62,6 & 10,9 & 36,0 \\
\hline K650-100 & 53,3 & $-13,0$ & $-5,7$ \\
\hline K550-100 & 27,2 & 17,4 & $-22,0$ \\
\hline K650-150 & 76,7 & 3,4 & 40,0 \\
\hline K750-150 & 65,1 & 13,3 & 37,4 \\
\hline K550-200 & 47,0 & $-5,2$ & $-3,2$ \\
\hline K650-200 & 77,8 & 1,1 & 22,6 \\
\hline K750-200 & 74,0 & 3,2 & 36,5 \\
\hline Ticari TiN & 68,5 & 8,7 & 41,4 \\
\hline
\end{tabular}



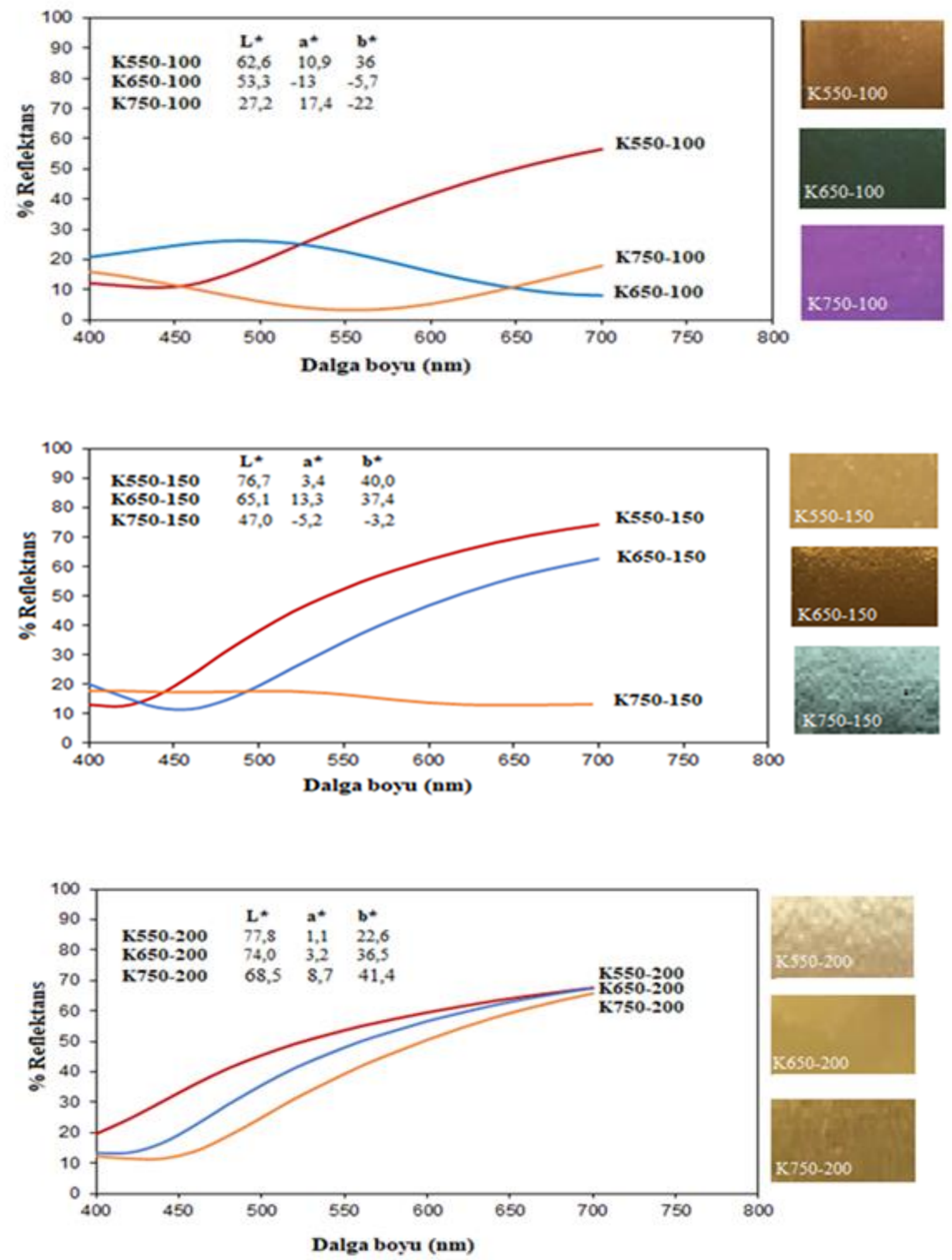

K750-200

Şekil 4. Kaplamaların spektrafotometre ile belirlenen görünür bölgeye ait reflektans eğrileri 


\section{Sonuçlar}

Bu çalışmada seramik karo yüzeyinde TiN bileşiminde altın renkde dekoratif kaplamalar üretmek için reaktif nitrojen gaz akış oranı ve katot akımı gibi proses parametreleri değiştirilerek Katodik Ark FBB yöntemi ile nitrürleme işlemi gerçekleştirilmiştir. Üretilen kaplamaların $L^{*} a * b *$ renk parametreleri ticari TiN kaplamalar ile kıyaslanarak TiN stokiyometrisine ve altın rengine en yakın proses parametreleri belirlenmiştir. Elde edilen sonuçlardan, ticari kaplamalara benzer renk paramerelerine $550 \mathrm{sccm}-150$ A ve $650 \mathrm{sccm}-200 \mathrm{~A}$ proses koşullarında üretilen kaplamalar ile ulaşılmıştır. Bu sonuçlardan Katodik Ark FBB tekniği ile seramik karo dekorasyonunda elek baskı tekniğine göre hem daha ekonomik ve seri üretime uygun hem de aşınma dayanımı daha yüksek altın benzeri kaplamalar üretilebileceği görülmüştür. Ayrıca altın rengin yanı sıra, farklı proses parametreleri ile mor, yeşil, kahve ve bakır gibi metalik efekt veren ve seramik karo dekorasyonunda uygulanabilecek alternatif kaplama renkleri de elde edilmiştir.

\section{Kaynaklar}

Alberdi, A.A., Lucas M.F., Belda P.A. and Bueno, Z.R.M., 2005. Method of producing ceramic tiles having a metallic finish and the tile thus produced. Europ. Patent No: EP 1498402 A1

Alves, L.A., Sagas, J.C., Damiao, A.J. and Fontana, L.C., 2015. Drude's model optical parameters and the color of $\mathrm{TiN}_{\mathrm{x}}$ films obtained through reflectivity measurements. Braz. J. Physics, 45, 59-63.

Kim, H.J. and Joun, M.S., 2007. Effects of deposition temperature and time on the surface characteristics of TiN-coated high-speed steel by arc ion plating. Journal of Mechanichal Science and Technology, 21, 575-584.

Larpkiattaworn, S., Chokwatvikul, C., Surinphong, S. and Termsuksaward, P., 2013. Properties of
(Ti,Al)N film prepared by PVD cathodic arc. Suranaree J. of Science and Technology, 20 (3), 221-226.

Lousa, A., Esteve, J., Mejia, J.P. and Devia, A., 2007. Influence of deposition pressure on the structural mechanical and decorative properties of TiN thin films deposited by cathodic arc evaporation, Vacuum, 81, 1507-1510.

Manova, D., Gerlach, J.W. and Mandl, S., 2010. Thin film deposition using energetic ions. Materials, 2, 4109-4141.

Mubarak, A., Hamzah, E. and Toff, M.R.M., 2005. Review of PVD techniques for hard coating, Jurnal Mekanikal, 20, 42-51.

Niyomsoan, S., Grant, W., Olson, D.L and Mishra, B., 2002. Variation of color in titanium and zirconium nitride decorative thin films. Thin Solid Films, 415,187-194.

Öncel, S., 2002. Katodik ark FBB yöntemi ile dekoratif amaçlı Cr-O-N kaplamaların üretilmesi, Yüksek Lisans Tezi, ITÜ Fen Bilimleri Enstitüsü, İstanbul, 68.

Richert M., Mazurkiewicz, A. and Smolik, J., 2010. Chromium carbide coatings obtained by the hybrid PVD methods. Journal of Achievements in Materials and Manufacturing Engineering, 43, 145-152.

Sönmezoğlu, S., Koç, M. ve Akın, S., 2012. İnce film üretim teknikleri. Erciyes Üniversitesi Fen Bilimleri Enstitüsü Dergisi, 28(5), 389-401.

Vaz, F., Machado, P., Rebouta, L. and Mendes, J.A., 2002. Physical and morphological characterization of reactively magrettron sputtered TiN films. Thin Solid Films, 421-428.

Zeghni, A., 2003. The effect of thin film coatings and nitriding on the mechanical properties and wear resistance of tool steel, Master Thesis, School of Mechanical and Manufacturing Engineering, Dublin City University, Dublin, 150. 